\title{
MIGRAÇÃO E ESCRAVIDÃO NO BRASIL: UMA ANÁLISE ACERCA DA LEI N 13.445/2017
}

\section{Robson Heleno da Silva ${ }^{1}$ \\ Valena Jacob ${ }^{2}$}

RESUMO: O presente trabalho visa a analisar a proteção jurídica conferida aos imigrantes pela nova lei de migração, visando identificar, a partir da pesquisa bibliográfica e do método dedutivo, como esta norma pode representar um avanço no combate à exploração de trabalho escravo de imigrantes no Brasil. Inicialmente será exposto atual cenário de exploração de imigrantes pelo trabalho escravo contemporâneo. Posteriormente, será feito o cotejo entre a antiga legislação (Estatuto do Estrangeiro) e a Lei 13.445/2017. Por fim, serão destacados os dispositivos da nova lei que contenham mecanismos aptos a auxiliar na proteção e no combate ao trabalho escravo de imigrantes.

Palavras-chave: Proteção; imigrantes; nova lei; exploração; trabalho escravo.

MIGRATION AND SLAVERY IN BRAZIL: AN ANALYSIS OF LAW No. 13.445/2017

\begin{abstract}
The present work aims to analyze the legal protection to immigrants by the new migration law, aiming to identify, from the bibliographic research and the deductive method, how this norm can represent an advance in the fight against the exploitation of slave labor of immigrants in Brazil. Initially will be exposed the current scenario of exploitation of immigrants by contemporary slave labor. Subsequently, we will make the comparison between the old legislation and Law 13.445/2017. Finally, we will highlight the provisions of the new law that contain mechanisms capable of helping to protect and combat slave labor of immigrants.
\end{abstract}

Keywords: Protection; immigrants; new law; exploration; slave labor.

\footnotetext{
${ }^{1}$ Advogado. Voluntário da Clínica de Direitos Humanos da Amazônia. Mestrando em Direito pelo Programa de Pós-Graduação em Direito da UFPA. Bolsista financiado pela Capes. E-mail: robson-hs@ @otmail.com.

${ }^{2}$ Doutora e Mestre em Direito pela UFPA. Professora da Graduação em Direito e do Programa de Pós Graduação em Direitos Humanos da UFPA; Diretora da Faculdade de Direito da UFPA e Pesquisadora da Clínica de Direitos Humanos da Amazônia/UFPA. e-mail: valena_jacob@yahoo.com.br
} 


\title{
INTRODUÇÃO
}

A história do Brasil e da formação da sociedade brasileira é marcada pela influência da imigração de estrangeiros. Primeiramente, destaca-se a chegada dos Portugueses, a partir do século XVI, que vieram para ocupar as terras "recém-descobertas" e explorar suas riquezas. Posteriormente, o país vivenciou o intenso fluxo do tráfico de africanos, para servirem como mão de obra escrava para os diversos ciclos produtivos que se desenvolveriam nos séculos subsequentes (BAENINGER, 2017, p. 10).

A partir de 1850, após a proibição do tráfico de escravos pela Lei Eusébio de Queiroz, o país vivenciaria um novo fluxo migratório, desta vez de imigrantes europeus, que vieram para o Brasil incentivados pelo Estado, para trabalhar na agricultura e na indústria em desenvolvimento. Este processo perdurou até as primeiras décadas do Século XX.

A este respeito, afirma Fernandes (2015, p. 20):

\begin{abstract}
Se no primeiro momento, após a descoberta, a chegada de imigrantes vinha atender aos interesses políticos e econômicos da Coroa Portuguesa, no século XIX os que aportaram no Brasil, na maior parte dos casos, estavam inseridos em processo migratório que tinha por objetivo atender à crescente demanda por mão de obra no setor agrícola. Com o passar do tempo, este contingente, em sua maioria, formado por europeus, com predomínio de italianos, foi recebendo outras nacionalidades. Do início do século XIX ao final da terceira década do século XX, mais de quatro milhões de estrangeiros teriam chegado ao Brasil.
\end{abstract}

No intervalo entre 1950 e 1970, o Brasil vivenciou uma redução no número de imigrações, sendo este período marcado pela intensificação nas migrações internas, de brasileiros se deslocando entre as diferentes regiões do país. Durante a década de 80, houve um forte movimento de emigração, ou seja, de saída de brasileiros para outros países.

No entanto, a partir da década de 90, observou-se um fluxo de imigrantes vindos, principalmente, de países vizinhos, da América do Sul. A partir de 2010, o processo de imigração se intensificou, marcado pela chegada de refugiados Haitianos e Sírios. Desde 2015, conforme dados do Alto Comissariado ONU para Refugiados - ACNUR, tem crescido o número de imigrantes Venezuelanos. Estes, em 2016, foram responsáveis por 33\% das solicitações de refúgio (ACNUR, 2016).

Contudo, embora se utilize o termo "imigrante" gênero que engloba as espécies refugiados e imigrantes em sentido estrito, é preciso destacar que ambos tratam de realidades completamente distintas. Os refugiados são vítimas de deslocamentos forçados, que são obrigados a sair de seus países de origem para fugir de perseguições, conflitos ou violações a 
direitos humanos. Imigrantes, por outro lado, são indivíduos que costumam deixar seus países em busca de melhores condições de vida.

Tal distinção nos é importante, tendo em vista os contornos do presente trabalho, que trata da análise da nova Lei de Migração (Lei $n^{\circ} 13.445 / 2017$ ), a qual embora contenha previsões relativas também aos refugiados, dispõe mais especificamente acerca da situação dos imigrantes, haja vista que a condição dos refugiados é disciplinada pelo Estatuto dos Refugiados (Lei ${ }^{\circ}$ 9.474/1997).

Portanto, o presente trabalho terá como elemento central a situação dos imigrantes, conquanto trate também acerca dos refugiados, haja vista que estes também são vítimas do trabalho escravo, bem como são alvo de algumas das previsões da Nova Lei de Migração.

Na sessão inicial do presente artigo, será feito um breve esboço acerca do atual cenário de exploração dos imigrantes em condições de trabalho análogas às de escravo, destacando os principais setores da cadeia produtiva onde são empregados e os principais traços como: nacionalidade, faixa etária, entrada regular no país, etc.

Na segunda sessão, será abordada a proteção jurídica conferida pelo ordenamento jurídico brasileiro aos imigrantes. Inicialmente, será analisada a antiga legislação, conhecida como Estatuto do Estrangeiro, para em seguida, analisar a Nova Lei de Migração, a fim de identificar avanços em relação à antiga norma.

Por fim, será feita a análise dos dispositivos da Lei 13.445/2017, a fim de identificar possíveis previsões que auxiliam direta ou indiretamente no combate à exploração do trabalho de imigrantes em condições análogas às de escravo. Buscar-se-á responder, com base na pesquisa bibliográfica, bem como do método dedutivo e documental, ao seguinte questionamento: em que medida a legislação atual pode representar um avanço no combate à exploração de trabalho escravo de imigrantes no Brasil?

\section{IMIGRANTES E O TRABALHO ESCRAVO NO BRASIL}

A exploração de trabalho em condições análogas às de escravo, doravante trabalho escravo contemporâneo, é uma infeliz realidade no Brasil. Formalmente abolida em 1888, após a edição da Lei Áurea, a escravidão evoluiu ao longo do tempo, assumindo contornos que permitissem sua existência de modo quase que intocada pela legislação brasileira. Somente em 
1995, mais de um século após a abolição, o Brasil reconheceria a existência de trabalho escravo em seu território.

Deste então, o Brasil tem se empenhado em combater o trabalho escravo, tanto por meio de ações políticas, quanto através de modificações na Constituição e na legislação infraconstitucional. Apesar dos esforços e, de 1995 até 2015, quase 50 mil trabalhadores terem sido resgatados ${ }^{3}$, o problema está longe de ser controlado.

A exploração de trabalho escravo se faz presente em diversos setores da cadeia produtiva no Brasil. Seja no meio rural (agricultura, pecuária e carvoarias), seja no meio urbano (construção civil e indústria têxtil), tem se observado a ocorrência da exploração de trabalhadores em situações que configuram as modalidades típicas e/ou equiparadas do artigo $149^{4}$, do Código Penal (LIMA, 2015. p. 62).

Esta, porém, não é uma realidade que afeta apenas os trabalhadores brasileiros. Pelo contrário, cada vez mais tem se observado a presença de estrangeiros dentre os trabalhadores resgatados. Sem falar em situações onde a mão de obra explorada é totalmente de imigrantes, na maioria das vezes em situação de ilegalidade no país, que são vítimas do tráfico de pessoas, ou são atraídos por falsas promessas.

Diversas são as nacionalidades das vítimas resgatadas, que costumam ser contratadas para trabalharem em diferentes nichos do mercado de trabalho. Geralmente, desempenham atividades que não costumam atrair brasileiros, dadas as condições degradantes a que o trabalhador é exposto, tendo como contrapartida salários baixos. Porém, aceitam tais condições, vez que se apresentam como uma possibilidade de sobrevivência (MORAIS, 2015, p. 11).

Neste sentido, destaca Villen (2015, p. 3):

A eles se apresenta restritivamente outra porta, que se abre emergencialmente, muitas vezes de forma subterrânea, e é direcionada a setores altamente marcados pela precarização do trabalho, como a indústria têxtil, de abate de carnes, construção civil, serviço doméstico, entre outros. Embora haja uma expressiva demanda desses setores por essa força de trabalho, não representam um canal de entrada legalizado para esses imigrantes e refugiados.

\footnotetext{
3 Conforme dados do Ministério do Trabalho. Disponível em: <http://reporterbrasil.org.br/dados/trabalhoescravo/>. Acesso em: 10.08.2017.

${ }^{4}$ Art. 149. Reduzir alguém a condição análoga à de escravo, quer submetendo-o a trabalhos forçados ou a jornada exaustiva, quer sujeitando-o a condições degradantes de trabalho, quer restringindo, por qualquer meio, sua locomoção em razão de dívida contraída com o empregador ou preposto:

Pena - reclusão, de dois a oito anos, e multa, além da pena correspondente à violência.

$\S 1$ o Nas mesmas penas incorre quem:

I - cerceia o uso de qualquer meio de transporte por parte do trabalhador, com o fim de retê-lo no local de trabalho; II - mantém vigilância ostensiva no local de trabalho ou se apodera de documentos ou objetos pessoais do trabalhador, com o fim de retê-lo no local de trabalho.
} 
Outro aspecto observado, diz respeito à especialização e preferência de trabalhadores de determinadas nacionalidades em executar certas atividades. Isto é evidenciado, principalmente, pela presença predominante de bolivianos na indústria de confecções (SILVA, 2012), e dos haitianos na construção civil.

Nas subseções a seguir, será feito um breve apanhado sobre tais casos de predomínio ${ }^{5}$ de nacionalidades em determinados setores, e os pontos característicos observados. Em vista dos limites deste trabalho, serão expostas apenas as situações dos imigrantes bolivianos e dos refugiados haitianos. Mas, ressalta-se que há estudos que constatam a predominância de imigrantes de origem afro-islâmica na indústria avícola halal (SILVA, 2013), bem como das mulheres peruanas em serviços domésticos (MARGALEF, 2012).

\subsection{O trabalho escravo de bolivianos na indústria de confecções}

A imigração de bolivianos para o Brasil não é recente, tendo seu início a partir da década de 50, e se intensificado após a década de 80 (FERNANDES, 2015). Embora dados do IBGE, relativos ao ano de 2010, apontem para a presença de 38.826 bolivianos residentes no Brasil, estima-se que este número seja muito maior, porém, não há como afirmar precisamente dada a condição de irregularidade com que muitos entram no país (SUZUKI, 2016).

Esse movimento migratório de bolivianos possui um cunho iminentemente econômico. Embora nos últimos anos, o país tenha vivenciado um crescimento econômico e uma redução da pobreza ${ }^{6}$, ainda padece de graves problemas relativos às elevadas taxas de desemprego, que afetam, principalmente, aqueles que não possuem formação superior. Tal fator faz com que muitos bolivianos migrem para o Brasil em busca de trabalho e melhores condições de vida (ALVES, 2012. p.234).

De acordo com o mencionado anteriormente, boa parte dos imigrantes bolivianos estão concentrados na cidade de São Paulo (SOUCHAUD, 2012), onde atuam nas confecções de roupas, em oficinas, na condição de trabalhadores autônomos ou subcontratados. Estes últimos é que costumam ser resgatados de situações de trabalho escravo, pelas fiscalizações do Ministério do Trabalho Emprego e Previdência Social e do Ministério Público do Trabalho.

\footnotetext{
${ }^{5}$ Ressalte-se que não se está a afirmar que somente bolivianos atuam na indústria de confecções, mas sim que tem se observado um predomínio de trabalhadores desta nacionalidade, no que tange aos resgates realizados em oficinas de costura.

${ }^{6}$ Disponível em: <https://economia.uol.com.br/noticias/efe/2016/01/20/bolivia-reduziu-pobreza-em-10-anos-demorales-mas-ve-nuvens-no-horizonte.htm>. Acesso em 09.08.2017.
} 
Estes trabalhadores costumam ser encontrados em espaços onde a oficina de costura e o local de moradia se confundem, sendo marcados pela insalubridade e ausência de condições dignas. A condição de entrada destes trabalhadores quase sempre é irregular, sendo que, muitos destes são aliciados ainda na Bolívia, sendo diretamente levados para as oficinas assim que chegam ao Brasil.

A este respeito, descreve Suzuki (2016, pp. 151-152):

Os contratos de trabalho são estabelecidos verbalmente. O valor da passagem é a primeira dívida estabelecida entre o imigrante e o aliciador. A entrada no país, quase sempre, é irregular - por meio da travessia de fronteiras terrestres com vistos de turistas ou documentos falsificados. $\mathrm{Na}$ viagem, a retenção de documentos por parte do empregador é comum: já em São Paulo, isso será utilizado para chantagear o imigrante, que não terá qualquer documento para fazer denúncia, por exemplo.

Tem-se aqui a já conhecida lógica do endividamento e de descontos na remuneração do trabalhador. Outrora denominada "sistema de aviamento", quando de sua utilização no período da exploração da borracha na Amazônia, atualmente é conhecida como truck system ${ }^{7}$. Independente do nome, persiste a lógica perversa de submeter o trabalhador a uma dívida impagável, obrigando-o a seguir executando o trabalho em razão deste compromisso.

Outro aspecto que merece destaque, diz respeito ao fato de que em fiscalizações realizadas em 2013 e 2014, foram resgatados trabalhadores em oficinas de costura subcontratadas de grifes conhecidas, como Zara, MOfficer, Le Lis Blanc, etc. Estas empresas terceirizavam a produção de suas peças para as oficinas que, por se utilizarem de trabalho escravo, cobravam preços abaixo do mercado. Assim, a grife se beneficiava da exploração do trabalho escravo, sem associar seu nome diretamente ao crime.

Cumpre destacar que estes trabalhadores são marcados por vulnerabilidades. Primeiramente, a vulnerabilidade social e econômica, que faz com que saiam de seus países em busca de melhores condições de vida. Posteriormente, ao chegar no Brasil, deparam-se com a barreira do idioma e do isolamento social a que são submetidos, vez que costumam ter sua mobilidade controlada, somente podendo sair quando autorizados e mediante vigilância.

Não obstante, há ainda a presença de uma vulnerabilidade no que diz respeito ao desconhecimento da legislação brasileira. Estes trabalhadores não possuem conhecimento acerca dos direitos que possuem, o que lhes torna passíveis de toda a sorte de abusos. Ademais, têm medo de realizar denúncias, visto que, na maioria das vezes, estão no país ilegalmente, e temem ser deportados de volta para a Bolívia.

\footnotetext{
${ }^{7}$ Prática vedada pelo artigo $462, \S \S 2^{\circ}$ e $3^{\circ}$, da Consolidação das Leis Trabalhistas.
} 
Sobre a vulnerabilidade dos bolivianos, afirma Brito Filho (2011, p. 128):

[...] imigrantes, como é o caso dos bolivianos que trabalham na indústria de confecção; arregimentados em local distante de onde vai haver a prestação de serviços; sem perspectiva de realizar outra atividade que garanta sua sobrevivência; sem o grau de conhecimento mínimo que lhes permita questionar, ainda que intimamente, as péssimas condições de trabalho que lhes são oferecidas. Mais. Por conta de todas essas condições, são altamente influenciáveis e, no mais das vezes, levados a crer que o que lhes é exigido é permitido por lei.

Observa-se, portanto, que a exploração de trabalho escravo de imigrantes bolivianos segue a lógica já conhecida do aliciamento e posterior endividamento das vítimas, para serem exploradas em troca de irrisória ou nenhuma remuneração. Sua condição de vulnerabilidade e o anseio por melhores condições de vida os tornam alvos fáceis da exploração.

\subsection{O trabalho escravo de haitianos na construção civil}

O Haiti possui uma formação histórica marcada pela instabilidade sociopolítica, por violência e desastres naturais, fatores que contribuem para que o país seja considerado o mais pobre da América $^{8}$, e um dos mais pobres do mundo. Em 2010 o Haiti foi vítima de um terremoto, que atingiu sua capital e imediações, destruindo boa parte das construções e matando diversos haitianos. Este desastre natural desestabilizou a já combalida economia do país, afetando diretamente sua população.

Iniciado em 2010, o fluxo migratório de haitianos para o Brasil se intensificou de fato a partir de 2011. Fugindo de um cenário de instabilidade política, violência, miséria econômica, e epidemias (AIDS e Cólera), os haitianos começaram a adentrar o país ilegalmente, utilizando as fronteiras de estados da região norte, como Acre, Amazonas, Roraima, Mato Grosso e Amapá.

De acordo com dados do Conselho Nacional de Imigração - CNIg, de 2011 a 2012, houve um crescimento de mais de $680 \%$ no número de pedidos de residência feitos por haitianos. Porém, este número tem diminuído desde então. A crime econômica que assola o Brasil pode ser apontada como um possível fator responsável por esta redução. Contudo, é

\footnotetext{
${ }^{8}$ Conforme o "Relatório do Desenvolvimento Humano" de 2015, publicado pelo Programa das Nações Unidas para o Desenvolvimento. Disponível em: 〈http://hdr.undp.org/sites/default/files/hdr15_overview_pt.pdf >. Acesso em 10.08.2017.
} 
importante destacar que o fluxo de haitianos ainda é alto. Em 2014, o maior número de pedidos de residência no Brasil foi de haitianos 9 .

Ademais, o Brasil tem adotado uma política de acolhida com relação aos haitianos. Desde janeiro de 2012, está em vigor a Resolução Normativa $n^{\circ}$ 97, do CNIg, que trata sobre a concessão de "visto humanitário" para haitianos, com base na Lei no 6.815/1980. Esta medida foi prorrogada em 2016, e deve vigorar até outubro do corrente ano ${ }^{10}$. Porém, este visto apenas garante a permanência no Brasil. As solicitações de refúgio são feitas junto ao Comitê Nacional para os Refugiados - CONARE, que emite um protocolo, que possibilita a emissão de Cadastro de Pessoa Física - CPF e a Carteira de Trabalho e Previdência Social - CTPS ao imigrante, enquanto aguarda manifestação sobre o pedido.

No entanto, esta política tem sido criticada em virtude da ausência de transparência com relação aos pedidos de refúgio, bem como na demora para emissão das decisões, que podem demorar até dois anos e meio. Ademais, embora tenham sua permanência garantida e o acesso a Carteira de Trabalho, não há garantias quanto ao acesso a oportunidades de emprego, regularização de documentos, ou aprendizado da língua portuguesa. Isto torna os haitianos presas fáceis da exploração pelo trabalho informal, em alguns casos, o trabalho escravo.

Embora se observe a presença de haitianos em diversas atividades, há uma predominância destes na construção civil. Conforme dados do Observatório de Migrações Internacionais - OBMigra ${ }^{11}$, em relatório divulgado em $2016^{12}$, no ano de 2015, foram formalmente contratados 3.050 haitianos, para atuar na construção civil. Embora, no mesmo ano, tenha havido um crescimento do número de contratações de haitianos para atividades em frigoríficos, a presença destes em canteiros de obras ainda se mostra bastante expressiva. Os haitianos são, em sua maioria, contratados para desempenhar a função de servente de obras, que requer o uso intenso da força física e pouca qualificação.

\footnotetext{
${ }^{9}$ De acordo com o relatório “Autorizações concedidas a estrangeiros", publicado em 2015 pela Coordenação Geral de Imigração - CGIg, órgão vinculado ao Ministério do Trabalho e Emprego - MTE, no ano de 2014, 1891 pedidos de residência foram feitos por haitianos através do Conselho Nacional de Imigração - CNIg. Disponível em: <https://oestrangeirodotorg.files.wordpress.com/2015/03/relatc3b3rio-cgig-final-completo-ult-versc3a3o.pdf>. Acesso em: 02.08.2017.

10 Disponível em: <http://www.brasil.gov.br/cidadania-e-justica/2016/09/governo-prorroga-visto-humanitariopara-haitianos>. Acesso em 01.08.2017.

${ }^{11}$ Iniciativa do Ministério do Trabalho e Emprego (MTE), por meio do Conselho Nacional de Imigração (CNIg) em parceria com a Universidade de Brasília (UNB).

${ }^{12}$ Relatório intitulado "A inserção dos imigrantes no mercado de trabalho brasileiro", divulgado em 2016, com dados referentes ao ano de 2015. Disponível em: <http://obmigra.mte.gov.br/index.php/relatorioanual/itemlist/category/74-2016>. Acesso em 05.08.2017.
} 
É nos canteiros de obra, que costumam ser flagrados casos de exploração de haitianos em condições de trabalho análogas às de escravo, sobretudo, na modalidade trabalho em condições degradantes. Como exemplo, pode-se citar o resgate, em 2013, de 100 haitianos que trabalhavam em uma obra da mineradora Anglo American, em Minas Gerais. Neste mesmo ano, 21 haitianos que trabalhavam em um canteiro de obras do programa Minha Casa Minha Vida, do Governo Federal, também foram resgatados, após uma fiscalização ter flagrado a ocorrência de condições degradantes ${ }^{13}$ nas frentes de trabalho e alojamentos ${ }^{14}$.

Observa-se, portanto, que, diferente dos bolivianos explorados nas oficinas de costura, a maioria dos haitianos está no Brasil em condição de legalidade, dada a política de facilitação na concessão do visto humanitário e de emissão de Carteiras de Trabalho. Isto faz com que a exploração do trabalho escravo, no caso dos haitianos, ocorra sob o manto de uma relação de trabalho formal. Estes são contratados para atuar na construção civil, e são submetidos a condições de trabalho degradantes, mesmo quando os empregadores são grandes empresas, vinculadas a projetos do Governo Federal.

\subsection{0 denominador comum}

Conforme foi possível observar, embora estejam em situações distintas, tanto imigrantes quanto refugiados estão passíveis de serem vítimas do trabalho escravo. Isto decorre não só da falta de políticas públicas voltadas para estas populações, mas, principalmente a aspectos inerentes à legislação voltada à proteção dos imigrantes.

Até o primeiro semestre deste ano, a lei que tratava acerca da situação dos imigrantes era o Estatuto do Estrangeiro, norma aprovada durante o período da ditadura militar, fortemente criticada por suas inconsistências face à Constituição Federal de 1988. Esta lei, no entanto, foi revogada pela Lei 13.445/2017, que trata da matéria e será alvo de análise nas próximas sessões.

Na sessão a seguir, tratar-se-á acerca da proteção conferida pela legislação brasileira aos imigrantes. Inicialmente, haverá uma breve descrição da antiga lei, o Estatuto do Estrangeiro, para que se possa cotejá-la à Nova Lei de Migração, aprovada em maio do corrente ano.

\footnotetext{
${ }^{13}$ Nestes casos, as vítimas resgatadas estavam em alojamentos sem condições adequadas de habitação, com superlotação e sem condições dignas de higiene. A alimentação fornecida aos trabalhadores era de baixa qualidade, pondo em risco a saúde dos trabalhadores.

${ }^{14}$ Disponível em: <http://reporterbrasil.org.br/2014/01/imigrantes-haitianos-sao-escravizados-no-brasil>. Acesso em 03.08.2017.
} 
Buscar-se-á, portanto, identificar possíveis avanços trazidos pelo novo dispositivo, no que diz respeito à proteção aos imigrantes.

\section{A PROTEÇÃO LEGAL AOS IMIGRANTES ONTEM E HOJE}

$\mathrm{Na}$ seção anterior, foi feita a exposição acerca da situação de vulnerabilidade dos imigrantes no Brasil, que faz com que estes sejam vítimas do trabalho escravo. Atribuiu-se a problemática não só à insuficiência de políticas públicas adotadas pelo Estado brasileiro, voltadas aos imigrantes, mas, também, a uma proteção legal deficiente.

Tendo em vista que a lei que tratava acerca da matéria até o primeiro semestre deste ano, o Estatuto do Estrangeiro, foi revogada com a edição da Nova Lei de Migração (Lei $n^{\circ}$ 13.445/2017), nesta sessão, será feita uma breve análise dos dois dispositivos, a fim de identificar em que medida houve avanços na proteção aos imigrantes.

\section{1 - O revogado Estatuto do Estrangeiro}

A lei $\mathrm{n}^{\circ}$ 6.815, conhecida como Estatuto do Estrangeiro, foi aprovada em 19 de agosto de 1980, dispondo sobre a definição da situação jurídica do estrangeiro no Brasil, e criação do Conselho Nacional de Imigração. Esta norma refletia a "doutrina da segurança nacional”, que despontou no cenário mundial durante o período da Guerra Fria, marcada um protecionismo exacerbado.

Este aspecto já ficava evidenciado nos três primeiros dispositivos da lei, vez que condicionavam a entrada, permanência e saída do estrangeiro (art. $1^{\circ}$ ), a concessão, prorrogação ou transformação de vistos ( $\operatorname{art.} 3^{\circ}$ ), bem como a aplicação da referida lei (art. $2^{\circ}$ ), à observância dos "interesses nacionais", que podem ser entendidos como aqueles referentes à segurança nacional, à organização institucional, aos interesses políticos, sócio- econômicos e culturais do Brasil, e à defesa do trabalhador nacional.

No que tange à concessão de visto para estrangeiros, destacava a previsão do artigo $7^{\circ}$, II, que disponha acerca da não concessão de visto a quem fosse considerado "nocivo à ordem pública ou aos interesses nacionais". Uma vez que a lei não estabelecia parâmetros, ficava o imigrante a mercê de subjetivismos. Ademais, havia ainda a previsão, no inciso $\mathrm{V}$, de “condições de saúde", a serem definidas pelo Ministério da Saúde, que deveriam ser observadas para a concessão de visto. 
O visto temporário, previsto no artigo 13, contemplava, basicamente, as situações de turismo, estudo e trabalho, condicionando o tempo de permanência conforme cada situação. Nas situações de trabalho, o prazo de estada no Brasil restava condicionado à "duração da missão, do contrato, ou da prestação de serviços". Não havia, portanto, previsão de um período para o imigrante que não estivesse amparado por um contrato de trabalho (compreenda-se aí, inclusive, aquele que ficasse desempregado antes do tempo).

No que concerne à concessão de visto permanente, a lei previa no parágrafo único, do artigo 16, o seguinte:

Art. 16. Parágrafo único. A imigração objetivará, primordialmente, propiciar mão-deobra especializada aos vários setores da economia nacional, visando à Política Nacional de Desenvolvimento em todos os aspectos e, em especial, ao aumento da produtividade, à assimilação de tecnologia e à captação de recursos para setores específicos.

Ou seja, a imigração tinha um caráter pragmático: somente seria concedido o visto permanente àqueles que atendesse aos "interesses nacionais", sobretudo no que tange ao desenvolvimento do país. Ainda assim, o artigo 18 condicionava a concessão de visto permanente ao prazo máximo de 5 (cinco) anos e ao "ao exercício de atividade certa e à fixação em região determinada do território nacional”. Logo, observa-se que havia um controle não só acerca da entrada, mas também do período e condições de permanência do imigrante.

Não obstante, ainda que houvesse a concessão do visto ao imigrante, este era definido pelo artigo 26 como sendo "mera expectativa de direito", de modo que a entrada, permanência ou registro do imigrante poderiam ser obstados se houvesse a ocorrência de quaisquer das hipóteses do artigo $7^{\circ}$, inclusive a já criticada previsão do inciso II e sua margem de subjetivismo. Ademais, se a presença do imigrante em território fosse considerada “inconveniente", também se aplicaria o impedimento do dispositivo. Ressalte-se que o impedimento de um membro, poderia se estender a todo o grupo familiar. A lei também não previa critérios para isto, de modo que é possível supor que havia aí também uma margem de insegurança ao imigrante.

No que diz respeito ao imigrante irregular, a legislação era expressa quanto a impossibilidade de legalizar a situação deste. O artigo 38 previa ser "vedada a legalização da estada de clandestino e de irregular, e a transformação em permanente, dos vistos de trânsito, de turista, temporário e de cortesia". Ou seja, ao imigrante que entrasse de modo irregular no país, só restava a deportação, vez que a lei impedia que este pudesse regularizar a sua situação e requerer a permanência. 
A deportação é prevista dos artigos 57 a 64 da lei, que versa sobre a retirada do território nacional imigrante que entrasse ou permanecesse irregular. Embora a lei contivesse a previsão acerca do estabelecimento de prazo para a saída voluntária, a ser fixado por Regulamento, caso houvesse "conveniência aos interesses nacionais”, a deportação poderia ocorrer independente da fixação de qualquer prazo para a saída voluntária (Art. 57, § $2^{\circ}$ ). Havia ainda a previsão de prisão do imigrante irregular, mediante ordem do Ministro da Justiça, independente da prática de qualquer delito, pelo prazo de 60 dias (Art. 61), prorrogável por mais 60 dias (parágrafo único).

Por fim, a lei previa que "não sendo exeqüível a deportação ou quando existirem indícios sérios de periculosidade ou indesejabilidade do estrangeiro, proceder-se-á à sua expulsão" (Art. 62). Ou seja, ao imigrante irregular que não pudesse ser deportado, restaria a expulsão em virtude de oferecer perigo aos "interesses nacionais", ou mesmo por sua presença não ser desejada no país.

De acordo com o mencionado anteriormente, o Estatuto do Estrangeiro pregava a proteção ao trabalhador brasileiro. Porém, tal proteção implicava em impor restrições ao estrangeiro, como a prevista no artigo 98. Conforme este dispositivo, o estrangeiro titular de visto de turista, de trânsito ou temporário, assim como seus dependentes, não poderiam exercer qualquer atividade remunerada no Brasil, sob pena de deportação ou retirada compulsória (expulsão ou extradição).

Esta previsão de vedação ao exercício de atividade remunerada deixava os imigrantes sujeitos a situações de exploração, que poderia configurar o crime trabalho escravo contemporâneo. Uma vez que não poderiam trabalhar formalmente, acabavam recorrendo ao trabalho irregular, tendo de se submeterem a toda a sorte de violações de direitos humanos e trabalhistas, sem poder efetuar denúncias, uma vez que poderiam ser obrigados a se retirar do país.

Por todo o exposto, é possível observar que o revogado Estatuto do Estrangeiro possuía previsões extremamente prejudiciais aos imigrantes. A "doutrina de segurança nacional" subjacente a todo o texto da norma, deixava os estrangeiros em situação de grave insegurança, a mercê da discricionariedade e da interpretação subjetiva dos aplicadores da lei.

As inconsistências desta norma ficam ainda mais evidentes, quando analisada à luz dos preceitos introduzidos no ordenamento jurídico brasileiro pela Constituição Federal de 1988. Direitos e garantias fundamentais, previstos no artigo $5^{\circ}$, o direito de ir e vir (XV), o 
princípio da individualização das penas (XLV), e a impossibilidade de prisão, salvo em situações de flagrante ou mediante ordem escrita de fundamentada de autoridade judiciária competente (LXI), são claramente violados pelas previsões dos artigos, 18, 26 e 61, respectivamente.

Logo, a revogação expressa do dispositivo, promovida pela Lei $n^{\circ}$ 13.445/2017 mostra-se como algo necessário. Resta saber, no entanto, em que pontos a nova lei trouxe avanços. Uma vez que se trata de uma lei editada sob a égide da Constituição Federal, faz-se necessário o seu estudo, a fim de identificar suas principais inovações em benefício dos imigrantes. Na subseção seguinte, será feita esta análise, apontando as principais modificações trazidas.

\section{2 - Lei no 13.445/2017 - A Nova Lei de Migração}

A Lei $n^{\circ}$ 13.445/2017, diferente da anterior, já afirma seus objetivos em seu primeiro dispositivo, quais sejam: dispor sobre os direitos e os deveres do migrante e do visitante, regulamentando a sua entrada e estada no País, estabelecendo princípios e diretrizes para as políticas públicas voltadas ao emigrante. Dispõe ainda sobre os sujeitos contemplados por suas normas (imigrantes, emigrantes, residentes fronteiriços, visitantes e apátridas), trazendo a definição de cada um deles.

Em seu artigo $2^{\circ}$, destaca sua compatibilidade para com normas internas e internacionais específicas sobre refugiados, asilados, agentes e pessoal diplomático ou consular, funcionários de organização internacional e seus familiares. Aqui cabe reiterar o mencionado no início deste trabalho com relação aos refugiados: conquanto estes sejam regidos pelo Estatuto dos Refugiados (Lei $n^{\circ}$ 9.474/1997), a Nova Lei de Migrações também possui previsões gerais que os contemplam, seja por meio de previsões ou pelo reconhecimento de sua condição.

Tendo por base os direitos e garantias previstos na Constituição Federal, os artigos $3^{\circ}$ e $4^{\circ}$ da lei voltam-se à previsão de princípios e diretrizes, e de direitos e garantias, respectivamente. São assegurados: a promoção e proteção aos direitos humanos, a igualdade, a integração e a acolhida humanitária aos imigrantes. Dentre os direitos, destacam-se os referentes às liberdades, a medidas de proteção e acesso a bens e serviços. Ressalte-se que estes direitos, conforme previsão expressa, devem ser exercidos à luz da Constituição Federal, independentemente da situação migratória (Art. $4^{\circ}, \S 1^{\circ}$ ) 
No que diz respeito aos vistos, a lei prevê um procedimento menos burocrático à concessão, dispondo inclusive acerca de possibilidades de simplificação do acesso (Art. $9^{\circ}$, caput e parágrafo único). Reduziram-se também as hipóteses de denegação do visto (não preenchimento de requisitos, condição impeditiva, ou menores de 18 desacompanhados ou sem autorização dos responsáveis ou autoridade competente), o que reflete uma clara mudança de perspectiva e superação da "doutrina da segurança nacional".

$\mathrm{O}$ artigo 14, que dispõe acerca do Visto Temporário, traz em seu $\S 3^{\circ}$ importante inovação, que merece transcrição integral, qual seja:

\begin{abstract}
Art. 14. $\S 3^{\circ}$ - O visto temporário para acolhida humanitária poderá ser concedido ao apátrida ou ao nacional de qualquer país em situação de grave ou iminente instabilidade institucional, de conflito armado, de calamidade de grande proporção, de desastre ambiental ou de grave violação de direitos humanos ou de direito internacional humanitário, ou em outras hipóteses, na forma de regulamento.
\end{abstract}

Esta previsão mostra-se importante, na medida em que assegura a qualquer estrangeiro em situação de risco o acolhimento no Brasil e, posteriormente, a solicitação de refúgio. Coaduna-se, portanto, ao previsto pela Declaração de Cartagena, de 1984, que contemplou ao conceito de refugiado, as vítimas de deslocamentos forçados em razão de conflitos e violações a direitos humanos.

A Declaração de Cartagena, na conclusão Terceira, de seu item III, acrescenta ao conceito de refugiado o seguinte:

Deste modo, a definição ou o conceito de refugiado recomendável para sua utilização na região é o que, além de conter os elementos da Convenção de 1951 e do Protocolo de 1967, considere também como refugiados as pessoas que tenham fugido dos seus países porque a sua vida, segurança ou liberdade tenham sido ameaçadas pela violência generalizada, a agressão estrangeira, os conflitos internos, a violação maciça dos direitos humanos ou outras circunstâncias que tenham perturbado gravemente a ordem pública.

Acerca desta ampliação do conceito, destaca Jubilut (2007, p. 135):

\begin{abstract}
A partir dessa ampliação a violação de quaisquer direitos humanos, e não somente dos direitos consagrados como civis e políticos, retomando a indivisibilidade dos direitos humanos, pode ensejar a proteção de alguém na condição de refugiado, assegurandose, de tal modo, o efetivo gozo dos direitos humanos pelos indivíduos.
\end{abstract}

Tem-se aí um importante avanço, na medida em que a nova lei não apenas revoga disposições restritivas, como também amplia a possibilidade de acolher imigrantes em razão de situações de ameaça. Ademais, outro avanço em relação à lei anterior, diz respeito à possibilidade de ser concedido ao imigrante o visto temporário para trabalho independentemente da existência de contrato de trabalho ou vínculo empregatício (Art. $14 \S 5^{\circ}$ ). 
Diferentemente da lei anterior, não há mais a previsão de "Visto permanente", mas sim em "Autorização de residência" (Art. 30), a qual se estende ao imigrante, residente fronteiriço ou ao visitante, mediante registro, independente de qualificação profissional, e sem estabelecer prazo ou condições de permanência. Há vedação na concessão apenas com relação à pessoa condenada criminalmente no Brasil ou no exterior por sentença transitada em julgado, desde que a conduta esteja tipificada na legislação penal brasileira $\left(\S 1^{\circ}\right)$. Ressalva-se, no entanto, as situações em que: a conduta caracterize infração de menor potencial ofensivo; ou a residência seja para tratamento de saúde, acolhida humanitária, reunião familiar, ou a pessoa seja beneficiária de tratado em matéria de residência e livre circulação.

No que diz respeito aos solicitantes de refúgio, de asilo ou de proteção ao apátrida, a lei assegura a estes a concessão de autorização provisória de residência até a obtenção de resposta ao seu pedido $\left(\S 4^{\circ}\right)$. A partir da nova lei, a concessão de autorização de residência independe da situação migratória $\left(\$ 5^{\circ}\right)$. Uma vez obtida a autorização para residência, sua perda ou cancelamento somente se dará se for constatada fraude ou ocultação de condição impeditiva de concessão de visto, de ingresso ou de permanência no País, sendo assegurado o contraditório e a ampla defesa ao estrangeiro no processo administrativo que a decretar.

No que concerne à deportação, a lei prevê que haja a notificação do estrangeiro irregular, para que proceda à regularização de sua situação no prazo de 60 (sessenta dias), o

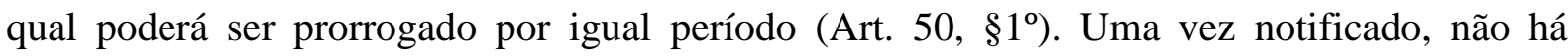
qualquer restrição à circulação do estrangeiro pelo território nacional $\left(\S 2^{\circ}\right)$. Findo o prazo sem regularização, pode haver deportação $\left(\S 3^{\circ}\right)$, tendo por base procedimentos que respeitem o contraditório e a ampla defesa, bem como a garantia de recurso com efeito suspensivo (Art. 51). Assegura-se ainda a prestação de assistência jurídica ao deportando pela Defensoria Pública (Art. 51, $\$ 1^{\circ}$ ).

Ou seja, diversamente do previsto na lei anterior, há todo um procedimento a ser observado para que haja a deportação, devendo-se assegurar todos os direitos e garantias ao estrangeiro irregular, facilitando-se ainda a regularização de sua situação. Não há qualquer previsão de prisão, uma vez que a lei nova tem como diretriz a "não criminalização da migração", conforme prevê o inciso III, do seu artigo $3^{\circ}$. Por fim, não há qualquer previsão de possibilidade de expulsão, caso não seja possível a deportação.

Destarte, a Nova Lei de Migração apresenta-se bastante progressista, se comparada para com o revogado Estatuto do Estrangeiro. As previsões contidas no dispositivo atual, 
mostram-se em sintonia não apenas com a Constituição Federal, mas também em relação às normas internacionais de Direitos Humanos.

Embora a Nova Lei traga ainda importantes previsões voltadas aos apátridas, asilados e residentes fronteiriços, bem como disponha acerca da naturalização e dos direitos do emigrante, tratam-se de inovações, cujo estudo deverá ser efetuado em trabalhos futuros, vez que o objetivo do presente estudo é apenas de comparar as evoluções trazidas pela Nova Lei, com relação a previsões contidas anteriormente no revogado Estatuto do Estrangeiro.

$\mathrm{Na}$ última seção do presente artigo será abordada as previsões contidas na Nova Lei que contenham mecanismos de proteção aptos a auxiliar na proteção aos trabalhadores imigrantes e no combate à submissão destes ao trabalho análogo ao de escravo.

\section{A LEI No 13.445/2017 E O COMBATE AO TRABALHO ESCRAVO}

Inicialmente, cumpre destacar que a Lei $\mathrm{n}^{\circ}$ 13.445/2017 traz em seu texto uma importante medida voltada para as vítimas de trabalho escravo. Diz respeito à previsão do artigo 30, II, g:

Art. 30. A residência poderá ser autorizada, mediante registro, ao imigrante, ao residente fronteiriço ou ao visitante que se enquadre em uma das seguintes hipóteses: II - a pessoa:

g) tenha sido vítima de tráfico de pessoas, de trabalho escravo ou de violação de direito agravada por sua condição migratória;

Ou seja, possibilita que aqueles estrangeiros que tenham sido vítimas de tráfico de pessoas e/ou submetidos a trabalho escravo, possam obter autorização de residência para permanecer no Brasil. Ora, conforme exposto em seção anterior, a situação dos bolivianos explorados pelo trabalho escravo em oficinas de costura é justamente essa: são traficados de seu país de origem para trabalharem em condições análogas à escravidão no Brasil.

A possibilidade de obter autorização para residência, se considerada em conjunto com possibilidade de regularização da condição de irregularidade assegurada, ambas resguardadas pela Nova Lei, podem ajudar a combater o trabalho escravo, na medida em que afeta diretamente a situação destes imigrantes irregulares escravizados, que não denunciam as situações a que são submetidos por temerem a deportação que, conforme tratado no tópico anterior, já não ocorre nos moldes do revogado Estatuto do Estrangeiro.

Não obstante, a segunda parte do dispositivo dispõe acerca da concessão de autorização de residência às vítimas de “violação de direito agravada por sua condição 
migratória". Esta previsão se adequa à situação dos refugiados e solicitantes de refúgio, ilustrada anteriormente pela situação dos haitianos. Diversamente dos bolivianos, estes costumam entrar no país regularmente, porém, acabam sendo vítimas da exploração pelo trabalho informal ou em condições análogas às de escravo, justamente em razão de sua condição de imigrantes.

Observa-se, portanto, que a referida disposição contempla ambos os sujeitos que costumam ser alvo do trabalho escravo: imigrantes e refugiados e solicitantes de refúgio. Há aqui, portanto, um mecanismo apto a produzir importantes resultados no combate ao trabalho escravo. Embora refira-se às vítimas de violações, o dispositivo pode evitar que haja a reincidência das vítimas, uma vez que podem regularizar sua situação, caso estejam irregulares, e permanecer no país, sem que sejam deportadas para o seu país de origem.

Outra previsão que pode auxiliar no combate ao trabalho escravo, é a contida no parágrafo $5^{\circ}$, do artigo 14 :

Art. 14 - § 5 Observadas as hipóteses previstas em regulamento, o visto temporário para trabalho poderá ser concedido ao imigrante que venha exercer atividade laboral, com ou sem vínculo empregatício no Brasil, desde que comprove oferta de trabalho formalizada por pessoa jurídica em atividade no País, dispensada esta exigência se o imigrante comprovar titulação em curso de ensino superior ou equivalente.

Conforme exposto anteriormente, esta previsão não apenas possibilita que o imigrante obtenha um visto de trabalho, ainda que esteja desempregado, como não impede que este ou seus dependentes exerçam atividade remunerada no Brasil.

$\mathrm{Na}$ exposição anterior, vimos que o revogado Estatuto do Estrangeiro vedava a possibilidade de exercício de atividade remunerada por estrangeiro titular de visto temporário, estendendo a vedação aos seus dependentes, sob pena de retirada compulsória. A vedação contida na lei revogada acabava por alimentar o ciclo de exploração dos imigrantes, na medida em que estes acabavam se sujeitando a trabalhos informais e em condições indignas, tendo seus direitos lesados, sem que pudessem denunciar as violações.

Assim, esta modificação, trazida pela Nova Lei, pode ser considerada também como um mecanismo de auxílio no combate ao trabalho escravo, na medida em que pode evitar que os trabalhadores imigrantes tenham que se submeter ao trabalho informal ou em condições análogas às de escravo, vez que se facilita agora a sua permanência no país para fins de trabalho.

Há ainda a previsão do artigo 38, que trata acerca de fiscalizações de passageiros a serem realizadas pela Polícia Federal em fronteiras, portos e aeroportos brasileiros. A lei determina que pode haver impedimento de ingresso quando, após entrevista individual e 
mediante ato fundamentado (Art. 45), a pessoa não apresentar documento de viagem (VI) ou apresente documento com rasura ou indício e falsificação $(\mathrm{V}, \mathrm{c})$.

Tais previsões visam a combater o tráfico de pessoas. Tendo em vista que boa parte dos imigrantes que entram de modo irregular no Brasil, para serem explorados pelo trabalho, são vítimas do tráfico, esta previsão também contém um potencial mecanismo de auxílio ao combate.

Por fim, destaca-se a previsão contida no artigo 115, que acrescentou ao Código Penal o artigo 232-A, que tipifica a conduta de "promoção de migração ilegal", visando punir, com pena de reclusão de 2 a 5 anos, e multa, aquele que "promover, por qualquer meio, com o fim de obter vantagem econômica, a entrada ilegal de estrangeiro em território nacional ou de brasileiro em país estrangeiro". Equipara-se ao delito a promoção "por qualquer meio, com o fim de obter vantagem econômica, da saída de estrangeiro do território nacional para ingressar ilegalmente em país estrangeiro", devendo a pena ser aumentada de 1/6 a 1/3 se o crime for cometido com violência ou se a vítima for submetida condição desumana ou degradante.

Esta previsão de um novo tipo penal representa, igualmente, um mecanismo de combate ao trabalho escravo, visto que visa a coibir a conduta dos chamados "coiotes", que são aliciadores que lucram com o traslado de imigrantes ilegais de seu país de origem para o Brasil. Ademais, a previsão do aumento de pena em decorrência da submissão a condição desumana ou degradante afeta diretamente aqueles aliciadores que conduzem os imigrantes diretamente ao trabalho escravo.

\section{CONCLUSÃO}

Conforme exposto no decorrer do presente trabalho, o Brasil vivencia atualmente um cenário marcado por um intenso fluxo migratório de entrada de estrangeiros, tanto vítimas de deslocamentos forçados, como aqueles que chegam ao Brasil em busca de melhores condições de trabalho e vida. No entanto, em muitos casos, estes imigrantes têm se deparado com um cenário de exploração, sendo, inclusive, submetidos a condições de trabalho análogas às de escravo.

De acordo com o exposto aqui, isto decorre não apenas de uma carência de políticas públicas voltadas a estas populações, mas, principalmente, a uma proteção legal insuficiente, que era conferida pelo Estatuto do Estrangeiro, uma legislação defasada, editada em um período 
de ditadura militar, em que prevalecia uma “doutrina de segurança nacional”, onde o estrangeiro era visto como inimigo em potencial.

No entanto, a revogação do Estatuto do Estrangeiro pela Lei nº 13.445/2017 (Nova Lei de Migração) descortina um novo cenário, mais favorável e acolhedor para os imigrantes. A mudança na perspectiva, sobretudo no que tange à previsão de direitos e garantias em conformidade com a Constituição Federal, demonstram que a Nova Lei tem por objetivo instituir um novo paradigma acerca das migrações.

Não obstante, a Nova Lei traz em seu bojo importantes mecanismos, aptos para auxiliar no combate à exploração do trabalho de imigrantes em condições análogas às de escravo. Diz-se “aptos”, pois se reconhece que a mera previsão legal, por si só, não é suficiente para assegurar a proteção dos imigrantes.

Neste sentido, vem à tona a necessidade de políticas públicas voltadas especificamente aos imigrantes. Uma vez que encontra-se em vigor uma nova legislação, é preciso que o poder público atue tanto no sentido de promover medidas para dar conhecimento desta lei aos destinatários, quanto para possibilitar que elas sejam efetivamente postas em prática.

Surgem, portanto, novos questionamentos a serem respondidos pelo Estado brasileiro: Como assegurar que a Nova Lei de Migração alcance a eficácia pretendida? Como garantir o acesso ao trabalho formal aos imigrantes num contexto de crise, onde inclusive os nacionais têm sido afetados pelo desemprego? Como evitar que os imigrantes sejam vítimas do trabalho escravo, se o problema afeta até os brasileiros?

\section{REFERÊNCIAS BIBLIOGRÁFICAS}

ACNUR. Dados sobre Refúgio no Brasil. 2016. Disponível em: <http://www.acnur.org/portugues/recursos/estatisticas/dados-sobre-refugio-no-brasil/>. Acesso em: 10.07.2017.

Declaração de Cartagena, 1984. Disponível em:

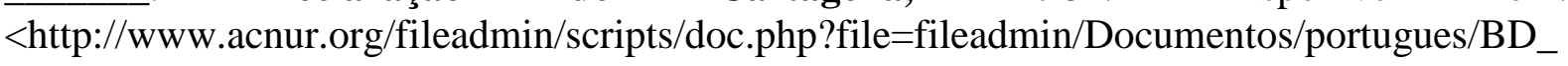
Legal/Instrumentos_Internacionais/Declaracao_de_Cartagena>. Acesso em: 12.07.2017.

ALVES, Ubiratan Silva. Imigrantes bolivianos em São Paulo: a Praça Kantuta e o Futebol. In: BOENINGER, Rosana (Org.). Imigração boliviana no Brasil. Campinas : Núcleo de Estudos de População-NEPO/Unicamp; Fapesp; CNPq; Unfpa. 2012.

ANDENA, Emerson Alves. TRANSFORMAÇÕES DA LEGISLAÇÃO IMIGRATÓRIA BRASILEIRA: os (des)caminhos rumo aos direitos humanos. 2013. Dissertação (Mestrado em Direitos Humanos) - Faculdade de Direito, Universidade de São Paulo, São Paulo. 2013. 
BAENINGER, Rosana. Migração transnacional: elementos teóricos para o debate. In: BAENINGER, Rosana; PERES, Roberta; FERNANDES, Duval; SILVA, Sidney Antonio da; ASSIS, Gláucia de Oliveira; CASTRO, Maria da Consolação G; CONTINGUIBA, Marília Pimentel (Orgs.). Imigração haitiana no Brasil. - Jundiaí : Paco Editorial, 2017.

BRASIL. Decreto-Lei n. 2.848, de 7 de dezembro de 1940. Código Penal. Publicado: D.O.U. de 31/12/1940. Disponível em: <http://www.planalto.gov.br/ccivil_03/decretolei/del2848compilado.htm>. Acesso em: 04.08.2017.

Lei $n^{\circ}$ 6.815, de 19 de agosto de 1980. Define a situação jurídica do estrangeiro no Brasil, cria o Conselho Nacional de Imigração. Publicado: D.O.U. de 21/08/1980. Disponível em: <http://www.planalto.gov.br/ccivil_03/leis/L6815.htm>. Acesso em 02.08.2017.

Lei $\mathbf{n}^{0}$ 13.445, de 24 de maio de 2017. Institui a Lei de Migração. Publicado: D.O.U. de 25/05/2017. Disponível em: <http://www.planalto.gov.br/ccivil_03/_ato20152018/2017/lei/L13445.htm>. Acesso em: 03.08.2017.

BRITO Filho, José Claudio Monteiro de. Trabalho escravo: elementos para a caracterização jurídica. In: FIGUEIRA, Ricardo Rezende et al. (org.). Trabalho escravo contemporâneo um debate transdisciplinar. Rio de Janeiro: Editora Mauad X, 2011a, p. 241-250.

FERNANDES, Duval. O Brasil e a migração internacional no século XXI - notas introdutórias. In: PRADO, Erlan José Peixoto do; COELHO, Renata (orgs.). Migrações e trabalho. - Brasília : Ministério Público do Trabalho, 2015.

FERNANDES, Duval; FARIA, Andressa Virgínia de. A diáspora haitiana no Brasil: processo de entrada, características e perfil. In: BAENINGER, Rosana; PERES, Roberta; FERNANDES, Duval; SILVA, Sidney Antonio da; ASSIS, Gláucia de Oliveira; CASTRO, Maria da Consolação G; CONTINGUIBA, Marília Pimentel (Orgs.). Imigração haitiana no Brasil. Jundiaí : Paco Editorial, 2017.

JUBILUT, L. L. O Direito internacional dos refugiados e sua aplicação no ordenamento jurídico brasileiro. São Paulo: Método, 2007.

LIMA, Camila Rodrigues Neves de Almeida. ESCRAVOS DA MODA: um estudo sobre a produção jurisprudencial brasileira em matéria de trabalho escravo nas oficinas de costura paulistanas. 2015. Dissertação (Mestrado em Ciências Jurídico-Empresarias) Faculdade de Direito, Universidade de Coimbra, Coimbra. 2015.

MARGALEF, Delia Maria Dutra da Silveira. Mulheres migrantes peruanas em Brasília: o trabalho doméstico e a produção do espaço na cidade. 2012. Tese (Doutorado em Sociologia) - Universidade de Brasília, Brasília. 2012.

MARTINS, Omar Conde Aleixo. Trabalho escravo urbano na construção civil - condições degradantes e a experiência do operariado vinculado ao Sindicato dos Trabalhadores da Indústria da Construção Civil e em frentes de obras em Belém do Pará. 2015. Dissertação 
(Mestrado em Direito) - Instituto de Ciências Jurídicas, Universidade Federal do Pará, Pará. 2015.

MORAIS, Paulo Tadeu. A imigração limítrofe e os bolivianos indocumentados na Grande São Paulo: os efeitos simbólicos das mudanças de práticas sociais. Disponível em: $<$ http://docplayer.com.br/12982435-A-imigracao-limitrofe-e-os-bolivianos-inducumentadosna-grande-sao-paulo-os-efeitos-simbolicos-das-mudancas-de-praticas-sociais.html>. Acesso em: 01.08.2017.

SILVA, Allan Rodrigo de Campos. Imigrantes afro-islâmicos na indústria avícola halal brasileira. 2013. Dissertação (Mestrado em Geografia Humana) - Faculdade de Filosofia, Letras e Ciências Humanas, Universidade de São Paulo, São Paulo. 2013.

SILVA, Silvana Cristina da. Circuito espacial produtivo das confecções e exploração do trabalho na metrópole de São Paulo. Os dois circuitos da economia urbana nos bairros do Brás e Bom Retiro (SP). 2012. Tese (Doutorado em Geografia Ambiental e Dinâmica Territorial) - Universidade Estadual de Campinas, São Paulo. 2012.

SUZUKI, Natalia. Bolivianos em cortiço onde e como vivem os imigrantes submetidos ao trabalho escravo na cidade de São Paulo. In: Discussões contemporâneas sobre trabalho escravo: teoria e pesquisa. $1^{\mathrm{a}} \mathrm{ed}$. Rio de Janeiro: Mauad X, 2016. pp. 147-165.

VILLEN, Patricia. Periféricos na periferia. In: ENCONTRO ANUAL DA ANPOCS, 39., 2015. Minas Gerais. Simpósios de Pesquisas Pós-Graduadas 24. Minas Gerais: Anpocs, 2015. Disponível em: <https://anpocs.com/index.php/papers-39-encontro/spg/spg24/9954perifericos-na-periferia/file>. Acesso em 03.08.2017. 